\title{
Ezrin expression is associated with hepatocellular carcinoma possibly derived from progenitor cells and early recurrence after surgical resection
}

\author{
Daiki Okamura, Masayuki Ohtsuka, Fumio Kimura, Hiroaki Shimizu, Hiroyuki Yoshidome, \\ Atsushi Kato and Masaru Miyazaki \\ Department of General Surgery, Graduate School of Medicine, Chiba University, Chiba, Japan
}

\begin{abstract}
Heterogeneous biological characteristics of hepatocellular carcinoma may be attributed to the cellular origin of the tumor. Patients with hepatocellular carcinoma probably derived from hepatic progenitor cells had early tumor recurrence after surgical resection or liver transplantation, suggesting that these tumors have aggressive characteristics. Ezrin, a member of the ERM (ezrin-radixin-moesin) cytoskeleton-associated protein family, is highly expressed in several types of human cancers and correlations between its immunoreactivity and patient outcome have been shown. In this study, ezrin expression, as well as cytokeratin19 and cytokeratin 7 expression, which are regarded as progenitor cell/ductular markers were immunohistochemically assessed in cases of hepatocellular carcinoma. In normal livers, ezrin expression was not found in any cell types, whereas cytokeratin 7 and cytokeratin 19 were exclusively stained in bile duct cells. In contrast, in livers with chronic hepatitis or cirrhosis, positive ezrin expression was observed in ductular reactions with strong intensity and intermediate hepatobiliary cells with various intensity. Of 77 cases of hepatocellular carcinoma, 28 (36\%) had positive ezrin expression, $32(42 \%)$ had cytokeratin 7 expression, and $11(14 \%)$ had cytokeratin 19 expression. Ezrin expression in hepatocellular carcinoma was significantly associated with cytokeratin 19 expression, but not with cytokeratin 7 expression. Patients with ezrin-positive hepatocellular carcinoma had a significantly higher prevalence of elevated serum $\alpha$-fetoprotein. Patients with immunohistochemical ezrin-positive hepatocellular carcinoma demonstrated significantly shorter recurrence-free and overall survival compared to patients with ezrin-negative hepatocellular carcinoma. Multivariate analysis revealed positive ezrin expression and multiple tumors to be independently associated with early recurrence in patients with hepatocellular carcinoma after curative surgical resection. These results suggested that hepatocellular carcinoma with ezrin expression might be at least partly derived from hepatic progenitor cells. Measurement of ezrin expression might be used to identify patients with an increased risk of early recurrence.
\end{abstract}

Modern Pathology (2008) 21, 847-855; doi:10.1038/modpathol.2008.59; published online 18 April 2008

Keywords: ezrin; progenitor cell; ductular reaction; hepatocellular carcinoma; cytokeratin 19

Hepatocellular carcinoma is the most common primary hepatic malignancy, especially in Africa and Asia, and its incidence is also rising in Western countries. ${ }^{1}$ Hepatic resection still has a major role in the treatments for hepatocellular carcinoma, and has achieved significant improvement of survival in patients with hepatocellular carcinoma in the past decade, which is now reported to exceed $50 \%$ at 5 years. ${ }^{2,3}$ However, the

Correspondence: Dr M Ohtsuka, MD, Department of General Surgery, Graduate School of Medicine, Chiba University, 1-8-1 Inohana, Chuoh-ku, Chiba 260-8670, Japan.

E-mail: otsuka-m@umin.ac.jp

Received 30 November 2007; revised and accepted 26 February 2008; published online 18 April 2008 rate of recurrence is still high after surgical resection,,$^{2,4}$ resulting in deterioration of the quality of life in some patients and leading to early mortality. Even among patients with a small solitary hepatocellular carcinoma, cases of early death due to recurrence have been encountered. ${ }^{5}$

In contrast, patients with long-term survival following resection for large hepatocellular carcinoma have also been reported. Pandey et $a l^{6}$ have reported that actuarial 5-year survival after surgical resection in patients with large hepatocellular carcinoma $(10 \mathrm{~cm}$ or more) was $28.6 \%$. These clinical experiences indicated that patients with hepatocellular carcinoma have a highly variable clinical course, suggesting that hepatocellular carcinoma has heterogeneous biological characteristics. 
Lee et $a l^{7}$ have shown that this heterogeneity was attributable to the cellular origin of the tumor. Patients with hepatocellular carcinoma that probably derived from hepatic progenitor cells, as indicated by a gene expression pattern, had a poor prognosis after surgical treatment. These cases of hepatocellular carcinoma expressed progenitor cell/ductular markers such as cytokeratin (CK)19 and/or CK7. Several studies ${ }^{8-11}$ have also shown that hepatocellular carcinoma having immunohistochemical CK19 expression was associated with a poor prognosis and a high rate of recurrence after surgical resection. Although the mechanisms whereby such types of hepatocellular carcinoma are associated with a poor prognosis and a high rate of recurrence after surgical resection have not been elucidated, it has been reported that several genes involved in tumor invasion and metastasis are upregulated in this type of hepatocellular carcinoma, including VIL2, which encodes ezrin. ${ }^{7}$

Ezrin is a member of the ERM (ezrin-radixinmoesin) cytoskeleton-associated protein family. Ezrin and the other ERM proteins act as linkers between the cell membrane and the actin cytoskeleton and are involved in several cellular functions, including cell adhesion to the extracellular matrix, cell-cell communication, signal transduction, and apoptosis. ${ }^{12,13}$ It has been reported that ezrin is implicated in cancer metastasis and progression through integration of cell surface receptors such as hepatocyte growth factor receptor, epidermal growth factor receptor and CD44, interaction with the signal-transduction molecules, and integration of cell adhesion molecules such as E-cadherin and integrins. ${ }^{13}$ The necessity of ezrin in the process of tumor cell growth, migration, and invasiveness in cases of hepatocellular carcinoma has also been demonstrated in vitro, ${ }^{14}$ although there have been no clinical studies on ezrin expression in hepatocellular carcinoma.

In this study, we therefore assessed expression of ezrin in hepatocellular carcinoma using clinical samples, and investigated the association of ezrin expression with clinical outcome in patients with hepatocellular carcinoma after curative surgical resection. We also assessed several clinicopathological parameters, including CK19 and CK7 expression.

\section{Materials and methods}

\section{Patients}

Seventy-seven consecutive patients with hepatocellular carcinoma who underwent curative surgical resection at Chiba University Hospital between January 1996 and December 2004 were included in this study. There were 60 men and 17 women, with a mean age of 64 years (range 28-79 years). Hepatocellular carcinoma was diagnosed on the basis of typical clinical and radiological findings, and also confirmed by histology. The histological definition of hepatocellular carcinoma was based on the classification proposed by the World Health Organization. ${ }^{15}$ Combined hepatocellular-cholangiocarcinoma was excluded in this study. Curative surgical resection was defined as resulting in a histologically cancer-negative margin. No patients received any preoperative treatment or postoperative adjuvant therapy.

After surgical resection, all patients were closely followed up at the outpatient clinic of the institution. Biochemical liver function and $\alpha$-fetoprotein (AFP) were measured every month. To determine tumor recurrence, computed tomography scans or ultrasonography were performed every 3 months for the first year and every 6 months thereafter. Bone metastasis was examined by scintigraphy with ${ }^{99 \mathrm{~m}} \mathrm{Tc}$ diphosphonate. All patients had a minimum of 42 months of follow-up, with a median follow-up period of 59 months (range 42-139 months). Recurrence was identified when new lesions were observed in imaging, including magnetic resonance imaging, with appearances typical of hepatocellular carcinoma. During the follow-up period, 50 patients $(65 \%)$ had recurrent tumors. The most common site of recurrence was the remaining liver. Metastasis to distant organs was recognized in 14 patients. After recurrence was diagnosed, chemotherapy by hepatic artery infusion was provided in 27 cases, surgical reresection was performed in 13 cases, percutaneous ablation therapy was provided in 3 cases, and only the best supportive care in 7 cases.

\section{Immunohistochemistry}

Immunohistochemical studies were conducted with an Envision +-Horseradish Peroxidase system (DakoCytomation, Glostrup, Denmark), using liver specimens (cancerous and non-cancerous tissues) obtained from patients with hepatocellular carcinoma at surgery. In addition, liver specimens obtained from seven patients with liver metastasis of colorectal cancer were also used in immunohistochemical studies. Samples showing no definite histological abnormality were used as 'normal liver.' The following were used as primary antibodies: mouse anti-human CK19 monoclonal antibody (clone RCK108; 1:100, DakoCytomation), mouse anti-human CK7 monoclonal antibody (clone OVTL 12/3.0; 1:100, DakoCytomation), and rabbit antiezrin polyclonal antibody (1:100, Cell Signaling Technology Inc., Danvers, MA, USA). Antigen was retrieved from deparaffinized and rehydrated tissues by microwave oven $\left(99^{\circ} \mathrm{C}, 20 \mathrm{~min}\right)$ in a $10 \mathrm{mM}$ sodium citrate buffer solution with a $\mathrm{pH}$ of 6.0. Diaminobenzidine was used as the chromogen, and sections were counterstained with hematoxylin. As a negative control, non-immunized mouse or rabbit immunoglobulin was substituted for the primary antibody. Expression of CK19 and CK7 
was considered positive if more than $5 \%$ of tumor cells were stained. Ezrin expression was evaluated on the basis of the intensity of staining and percentage of stained cells, as reported previously. ${ }^{16}$ Staining of any level of staining intensity in more than $10 \%$ of tumor cells was considered positive.

\section{Clinicopathological Parameters}

Age and gender of patients were recorded. Presence of hepatitis B or C virus, preoperative platelet count, level of preoperative serum alanine aminotransferase, aspartate aminotransferase, total bilirubin and albumin, and histological liver damage were evaluated as parameters related to liver function. Type of hepatic resection, operation time, and blood loss were recorded as surgical parameters. Preoperative serum AFP level, size of principal tumor, tumor number, macroscopic tumor invasion to large vessels, microscopic vascular invasion, and histological tumor differentiation according to pathological tumor node metastasis (pTMN) classification ${ }^{17}$ were included as tumor-related parameters.

\section{Statistics}

Data were analyzed using the Fischer's probability test, the $\chi^{2}$ test, and the Mann-Whitney $U$-test, to evaluate the significance of differences between the groups. Cumulative survival was calculated by the Kaplan-Meier method, and differences were examined using the log-rank test. The Cox proportional hazards model was used for multivariate regression analysis. $P<0.05$ was considered statistically significant.

\section{Results}

\section{Ezrin, CK7, and CK19 Expression in Normal and} Diseased Livers

In normal livers, ezrin expression was not found in any cell types, whereas CK7 and CK19 were exclusively stained in bile duct cells (Figure 1). In contrast, in livers with chronic hepatitis or cirrhosis obtained from patients with hepatocellular carcinoma, positive ezrin expression was observed in bile duct cells with weak intensity, ductular reaction with strong intensity, intermediate hepatobiliary cells with varying intensity, and infiltrating cells in and around portal tract (Figure 1). Ductular reactions and some intermediate hepatobiliary cells also stained positive for CK7 (Figure 1) and CK19.

\section{Ezrin, CK7, and CK19 Expression in Hepatocellular Carcinoma}

Of 77 cases of hepatocellular carcinoma, 28 (36\%) displayed positive ezrin immunoreactivity with variable staining intensity in tumor cells (Figure 2). In addition to tumor cells, infiltrating cells into the cancer tissues also stained positive for ezrin. Expression of CK7 was observed in 32 cases of hepatocellular carcinoma (42\%), and expression of CK19 in 11 (14\%) (Figure 2). Forty-two cases of hepatocellular carcinoma (55\%) were CK7 $(-) /$ CK19(-), 24 (31\%) were CK7(+)/CK19(-), 3 (4\%) were CK7 $(-) / \mathrm{CK} 19(+)$, and $8(10 \%)$ were CK7 $(+) /$ CK19 $(+)$.

\section{Relationship between Ezrin and CK Expression}

Ezrin expression in hepatocellular carcinoma was significantly associated with CK19 expression $(P=0.001): 9$ of 28 cases of hepatocellular carcinoma with positive ezrin expression had CK19 expression, whereas positive CK19 expression was found in only 2 of 49 cases of hepatocellular carcinoma without ezrin expression. In contrast, the relationship between ezrin and CK7 expressions was not statistically significant: 12 of 28 cases of hepatocellular carcinoma with positive ezrin expression and 20 of 49 cases of hepatocellular carcinoma without ezrin expression had CK7 expression.

\section{Comparison of Cases of Hepatocellular Carcinoma with and without Ezrin Expression}

Table 1 summarizes the relationship of immunohistochemical ezrin expression to various clinicopathological parameters. Patients with ezrin expression had a significantly higher prevalence of elevated serum AFP. No significant differences in age and gender of patients, presence of hepatitis B or C virus, preoperative platelet count, level of preoperative serum alanine aminotransferase, aspartate aminotransferase, total bilirubin and albumin, histologic liver damage, type of hepatic resection, operation time, blood loss, size of principal tumor, tumor number, macroscopic tumor invasion to large vessels, microscopic vascular invasion, or histologic tumor differentiation were found between cases of hepatocellular carcinoma with and without ezrin expression.

\section{Ezrin Expression and Outcome after Curative Surgical Resection}

Patients with immunohistochemical ezrin-positive hepatocellular carcinoma had significantly shorter recurrence-free and overall survival than patients with ezrin-negative hepatocellular carcinoma (Figure 3). In 15 out of 16 patients with ezrinpositive hepatocellular carcinoma who had tumor recurrence in the remaining liver, the recurrence occurred within 30 months after surgical resection. The incidence of extrahepatic metastasis was almost 

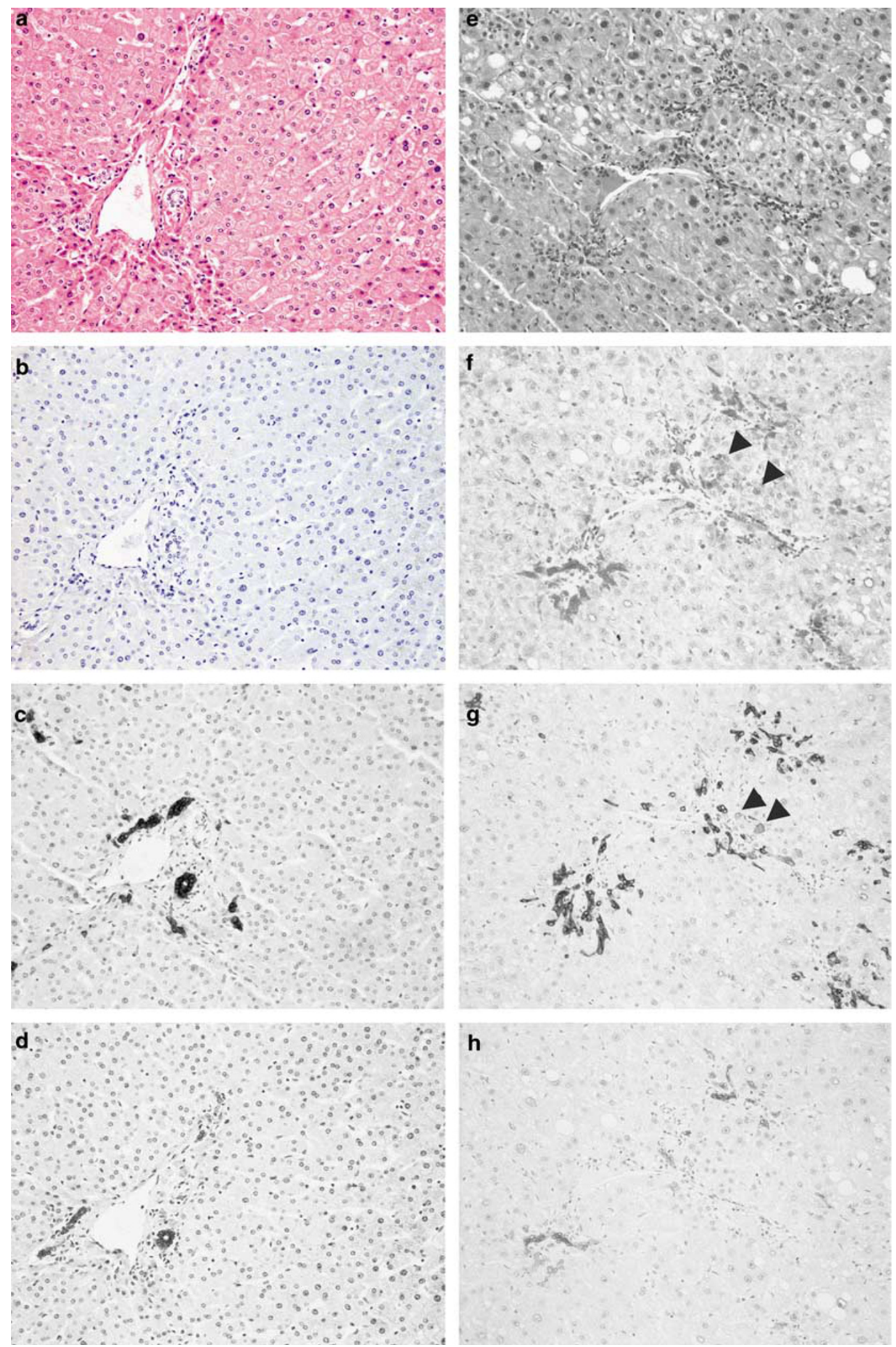

Figure 1 Immunohistochemical staining for ezrin (b and f), cytokeratin (CK)7 (c and g), and CK19 (d and h) in normal liver and the liver with ductular reactions. (a and e) Hematoxylin and eosin staining. (b and f) Ezrin was not detected in normal liver, whereas expression of ezrin was observed in ductular reactions and some of the intermediate hepatobiliary cells (arrowheads). (c and g) CK7 was stained in normal bile duct epithelium, ductular reactions, and some of the intermediate hepatobiliary cells (arrowheads). (d and h) CK19 expression was shown in normal bile duct epithelium and ductular reactions. 

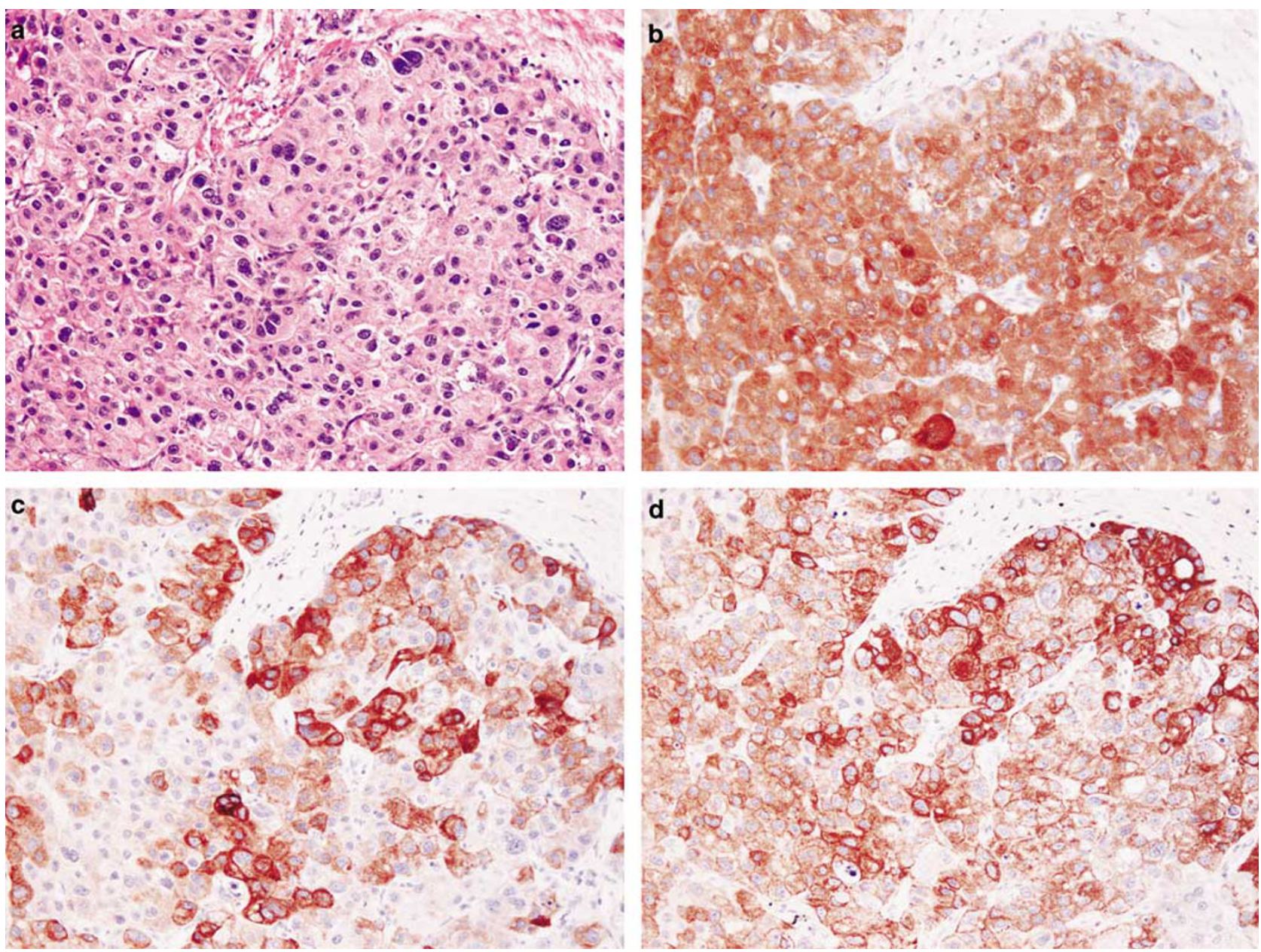

Figure 2 Representative ezrin, cytokeratin (CK)7, and CK19 expressions in hepatocellular carcinoma. (a) Hematoxylin and eosin staining. (b) Ezrin expression. (c) CK7 expression. (d) CK19 expression.

equal in patients with $(n=6)$ and without $(n=8)$ ezrin expression.

\section{Analysis of Factors Related to Recurrence-Free Survival}

Among clinicopathological parameters, univariate analysis showed that high serum AFP level, multiple tumors, macroscopic tumor invasion to large vessels, microscopic vascular invasion, presence of underlying liver disease (chronic hepatitis and cirrhosis), high volume of operative blood loss, and positive immunohistochemical ezrin expression were significant negative factors for recurrence-free survival (Table 2). Multivariate analysis revealed that positive ezrin expression and multiple tumors were independently associated with early recurrence after curative surgical resection (Table 3).

\section{Discussion}

Similarly to cases with acute massive hepatic necrosis, it is now generally accepted that hepatic progenitor compartment is also activated in chronic hepatitis, even with mild degrees of inflammation, irrespective of the underlying disease. ${ }^{18,19}$ Progenitor cell activation is usually observed in the form of ductular reaction. ${ }^{20,21}$ Ductular reaction in cases of chronic hepatitis represents highly proliferative cells with ductular phenotype such as CK7 and CK19, branching from the biliary tree. These cells could differentiate toward hepatocytes by intermediate hepatobiliary cells. In this study, ezrin expression was strongly observed in these cells. As growth factors including hepatocyte growth factor and epidermal growth factor have been shown to be required for survival, motility, and proliferation of oval cells (which is the rodent equivalent of human hepatic progenitor cells) in rats, ${ }^{22,23}$ ezrin may also play an important role in signal transduction elicited by growth factor receptors in human hepatic progenitor cells.

Activation of progenitor cell compartments in chronic hepatitis implies that they are vulnerable to genetic alternation, leading to carcinogenesis. Several previous reports ${ }^{7,10,11,24}$ have shown that some cases of hepatocellular carcinoma develop 
Table 1 Difference of clinicopathological features according to ezrin expression in patients with hepatocellular carcinoma

\begin{tabular}{|c|c|c|c|}
\hline & \multicolumn{2}{|c|}{ Ezrin expression } & \multirow[t]{2}{*}{ P-value } \\
\hline & Positive $(\mathrm{n}=28)$ & Negative $(\mathrm{n}=49)$ & \\
\hline Mean age (years) & $62 \pm 10$ & $65 \pm 10$ & 0.13 \\
\hline Male/Female & $20: 8$ & $40: 9$ & 0.39 \\
\hline \multicolumn{4}{|l|}{ Parameters related to liver function } \\
\hline Presence of hepatitis virus (serological) & 24 & 34 & 0.17 \\
\hline Platelet count $\left(<15 \times 10^{4} / \mu \mathrm{l}\right)$ & 13 & 25 & 0.81 \\
\hline Serum alanine aminotransferase $(\geq 45 \mathrm{IU} / \mathrm{l})$ & 16 & 26 & 0.81 \\
\hline Serum asparate aminotransferase ( $\geq 40 \mathrm{IU} / \mathrm{l})$ & 19 & 23 & 0.10 \\
\hline Serum total bilirubin $(\geq 1.2 \mathrm{mg} / 100 \mathrm{ml})$ & 3 & 10 & 0.35 \\
\hline Serum albumin $(<4 \mathrm{~g} / 100 \mathrm{ml})$ & 18 & 26 & 0.47 \\
\hline Presence of underlying diseased liver (histological) & 24 & 37 & 0.39 \\
\hline \multicolumn{4}{|l|}{ Parameters related to surgery } \\
\hline Anatomic hepatic resection & 19 & 39 & 0.28 \\
\hline Operative time ( $\geq 300 \mathrm{~min}$ ) & 13 & 23 & $>0.99$ \\
\hline Operative blood loss $(\geq 800 \mathrm{ml})$ & 14 & 24 & $>0.99$ \\
\hline \multicolumn{4}{|l|}{ Parameters related to tumors } \\
\hline Serum $\alpha$-fetoprotein $(\geq 200 \mathrm{U} / \mathrm{l})$ & 15 & 11 & 0.01 \\
\hline Size of principal tumor $(<2 \mathrm{~cm}: \geq 2 \mathrm{~cm},<5 \mathrm{~cm}: \geq 5 \mathrm{~cm})$ & $2: 16: 10$ & $5: 22: 22$ & 0.58 \\
\hline Tumor number (single/multiple) & $19: 9$ & $35: 14$ & 0.80 \\
\hline Presence of macroscopic invasion to the large vessels & 6 & 3 & 0.07 \\
\hline Presence of microscopic vascular invasion & 18 & 22 & 0.10 \\
\hline Differentiation $^{\mathrm{a}}(\mathrm{G} 1 / \mathrm{G} 2 / \mathrm{G} 3)$ & $0: 26: 2$ & $4: 40: 5$ & 0.26 \\
\hline
\end{tabular}

${ }^{\mathrm{a}}$ According to the pathological tumor node metastasis (pTMN) classification. ${ }^{17}$
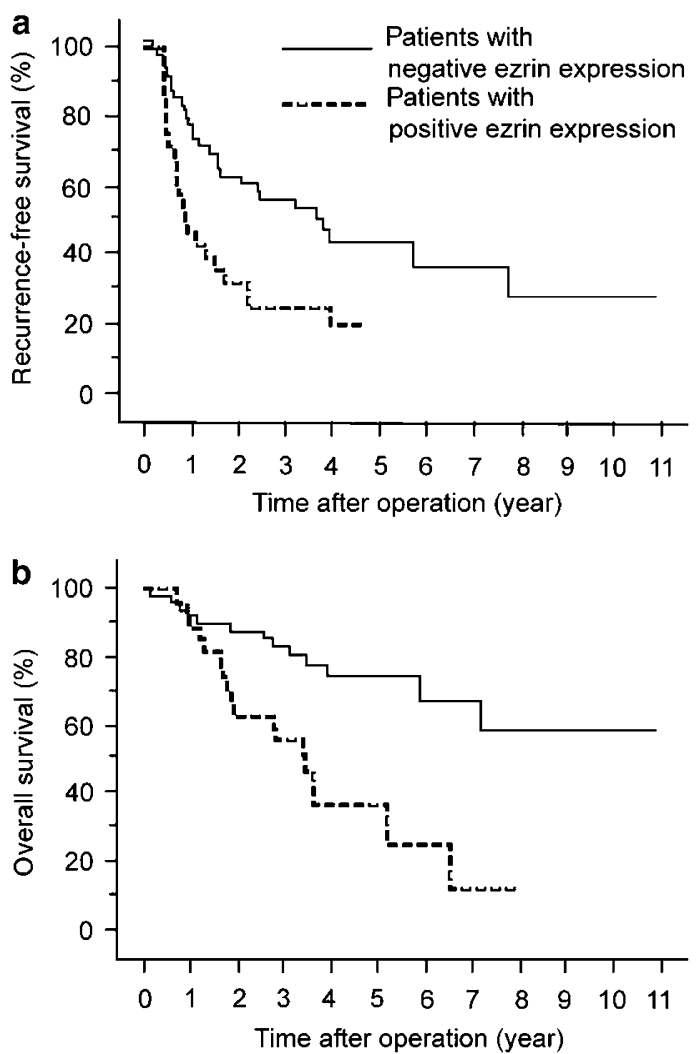

Figure 3 Overall (b) and recurrence-free survival (a) in patients with hepatocellular carcinoma after surgical resection, according to immunohistochemical ezrin expression. A significant difference was observed between patients with negative and positive ezrin expression $(P<0.01)$. through this carcinogenetic mechanism. These tumors usually showed phenotypical features of their cell of origin, such as progenitor cell/ductular markers. In particular, CK19 has been shown to be one of the most useful markers for cases of hepatocellular carcinoma that may be derived from progenitor cells. ${ }^{7,10,11,24}$ In this study, expression of ezrin, which was already expressed in progenitor cell compartments as mentioned above, was significantly associated with CK19 expression in hepatocellular carcinoma. Although not all cases of hepatocellular carcinoma with ezrin expression had CK19 expression, these results suggest that at least some cases of hepatocellular carcinoma with ezrin expression are derived from hepatic progenitor cells. The association of ezrin expression with high serum AFP, which is also a marker of progenitor cell compartments, ${ }^{25}$ is compatible with a progenitor cell origin for these tumors. The fact that some cases of hepatocellular carcinoma with ezrin expression showed negative CK19 expression may be due to the fact that cases of hepatocellular carcinoma that are consistent with a progenitor cell origin may not necessarily have positive CK19 expression, as previously described. ${ }^{10}$ Several studies using detailed immunophenotyping, with CK19, CK7, or OV6 for example, showed that $28-50 \%$ of cases of hepatocellular carcinoma derive from progenitor cells and their progeny, ${ }^{9,11,25,26}$ a frequency that is compatible with cases of hepatocellular carcinoma with ezrin expression. No specific marker for hepatic progenitor cell compartment has yet been described. 
Table 2 Univariate analysis of factors related to recurrence-free survival in patients with hepatocellular carcinoma

\begin{tabular}{|c|c|c|}
\hline & $\begin{array}{c}\text { Median recurrence } \\
\text { free-survival (months) }\end{array}$ & P-value \\
\hline \multicolumn{3}{|l|}{ Age (years) } \\
\hline$\geq 65(n=39)$ & 29.4 & 0.20 \\
\hline$<65(n=38)$ & 17.7 & \\
\hline \multicolumn{3}{|l|}{ Gender } \\
\hline Male $(n=60)$ & 24.7 & 0.79 \\
\hline Female $(n=17)$ & 19.8 & \\
\hline \multicolumn{3}{|c|}{ Serological hepatitis viral status } \\
\hline Positive $(n=58)$ & 24.7 & 0.33 \\
\hline Negative $(n=19)$ & 18.6 & \\
\hline \multicolumn{3}{|l|}{ Platelet count } \\
\hline$\geq 15 \times 10^{4} / \mu \mathrm{l}(n=38)$ & 38.5 & 0.27 \\
\hline$<15 \times 10^{4} / \mu \mathrm{l}(n=39)$ & 18.6 & \\
\hline \multicolumn{3}{|c|}{ Serum alanine aminotransferase } \\
\hline$\geq 45 \mathrm{IU} / \mathrm{l}(n=34)$ & 15.8 & 0.06 \\
\hline$<45 \mathrm{IU} / \mathrm{l}(n=43)$ & 38.5 & \\
\hline \multicolumn{3}{|c|}{ Serum asparate aminotransferase } \\
\hline$\geq 40 \mathrm{IU} / \mathrm{l}(n=42)$ & 18.6 & 0.06 \\
\hline$<40 \mathrm{IU} / \mathrm{l}(n=35)$ & 45.8 & \\
\hline \multicolumn{3}{|l|}{ Serum total bilirubin } \\
\hline$\geq 1.2 \mathrm{mg} / 100 \mathrm{ml}(n=15)$ & 43.5 & 0.97 \\
\hline$<1.2 \mathrm{mg} / 100 \mathrm{ml}(n=62)$ & 19.8 & \\
\hline \multicolumn{3}{|l|}{ Serum albumin } \\
\hline$\geq 4 \mathrm{~g} / 100 \mathrm{ml}(n=33)$ & 43.5 & 0.06 \\
\hline$<4 \mathrm{~g} / 100 \mathrm{ml}(n=44)$ & 17.1 & \\
\hline \multicolumn{3}{|c|}{ Underlying diseased liver (histological) } \\
\hline Positive $(n=61)$ & 17.7 & 0.04 \\
\hline Negative $(n=16)$ & 68.6 & \\
\hline \multicolumn{3}{|l|}{ Anatomic hepatic resection } \\
\hline Yes $(n=58)$ & 26.6 & 0.33 \\
\hline No $(n=19)$ & 15.8 & \\
\hline \multicolumn{3}{|l|}{ Operative time } \\
\hline$\geq 300 \min (n=36)$ & 14.1 & 0.10 \\
\hline$<300 \min (n=41)$ & 38.5 & \\
\hline \multicolumn{3}{|l|}{ Operative blood loss } \\
\hline$\geq 800 \mathrm{ml}(n=38)$ & 15.8 & 0.02 \\
\hline$<800 \mathrm{ml}(n=39)$ & 43.5 & \\
\hline \multicolumn{3}{|l|}{ Serum $\alpha$-fetoprotein } \\
\hline$\geq 200 \mathrm{U} / \mathrm{l}(n=26)$ & 12.7 & 0.03 \\
\hline$<200 \mathrm{U} / \mathrm{l}(n=51)$ & 43.5 & \\
\hline \multicolumn{3}{|l|}{ Size of principal tumor } \\
\hline$<2 \mathrm{~cm}(n=7)$ & 93.1 & 0.80 \\
\hline$\geq 2 \mathrm{~cm},<5 \mathrm{~cm}(n=38)$ & 24.7 & \\
\hline$\geq 5 \mathrm{~cm}(n=32)$ & 14.1 & \\
\hline \multicolumn{3}{|l|}{ Tumor number } \\
\hline Single $(n=54)$ & 38.5 & 0.02 \\
\hline Multiple $(n=23)$ & 14.1 & \\
\hline \multicolumn{3}{|c|}{ Macroscopic invasion to the large vessels } \\
\hline Positive $(n=9)$ & 12.7 & 0.006 \\
\hline Negative $(n=68)$ & 29.0 & \\
\hline \multicolumn{3}{|c|}{ Microscopic vascular invasion } \\
\hline Positive $(n=40)$ & 12.1 & 0.04 \\
\hline Negative $(n=37)$ & 43.5 & \\
\hline
\end{tabular}

Table 2 Continued

\begin{tabular}{lcc}
\hline & $\begin{array}{c}\text { Median recurrence } \\
\text { free-survival (months) }\end{array}$ & P-value \\
\hline Differentiation & & \\
G1 $(n=4)$ & 43.5 & 0.64 \\
G2 $(n=66)$ & 19.8 & \\
G3 $(n=7)$ & 38.5 & \\
Ezrin expression & & 0.009 \\
Positive $(n=28)$ & 9.9 & \\
$\quad$ Negative $(n=49)$ & 43.5 & \\
\hline
\end{tabular}

${ }^{a}$ According to the pathological tumor node metastasis (pTMN) classification. ${ }^{17}$

Table 3 Multivariate analysis of factors related to recurrence-free survival in patients with hepatocellular carcinoma

\begin{tabular}{|c|c|c|}
\hline Factors & Relative risk & $\mathrm{P}$-value \\
\hline $\begin{array}{l}\text { Presence of the underlying diseased } \\
\text { liver }\end{array}$ & $1.96(0.86-4.46)$ & 0.11 \\
\hline Operative blood loss $(\geq 800 \mathrm{ml})$ & $1.54(0.82-2.90)$ & 0.18 \\
\hline Serum $\alpha$-fetoprotein $(\geq 200 \mathrm{U} / \mathrm{l})$ & $1.37(0.72-2.58)$ & 0.34 \\
\hline Tumor number (multiple) & $2.01(1.12-3.91)$ & 0.02 \\
\hline $\begin{array}{l}\text { Macroscopic invasion to the large } \\
\text { vessels }\end{array}$ & $1.46(0.59-3.66)$ & 0.42 \\
\hline Microscopic vascular invasion & 1.4 & 0.26 \\
\hline Positive ezrin expression & $1.88(1.04-3.40)$ & 0.04 \\
\hline
\end{tabular}

Values in parentheses are $95 \%$ confidence intervals.

Alternatively, it is possible that hepatocellular carcinoma acquires ezrin expression during carcinogenesis.

CK7 is also regarded as a progenitor cell/ductular marker. However, CK7 expression in hepatocellular carcinoma was not associated with ezrin expression. Discrepancies between CK7 and CK19 expressions have often been observed in cases of hepatocellular carcinoma, in association with other clinicopathological factors. In this regard, Durnez et $a l^{10}$ suggested that CK7 expression in hepatocellular carcinoma could be a secondary phenomenon similar to CK7 expression in non-neoplastic, cholestatic hepatocytes that has been described. In primary biliary cirrhosis aberrant expression of CK7 by hepatocytes correlates with the degree of cholestasis. ${ }^{27}$ These results suggest that CK7 expression in hepatocellular carcinoma did not merely reflect the origin of tumor cells.

Several reports ${ }^{8-11}$ have shown that patients with hepatocellular carcinomas probably derived from hepatic progenitor cells had early tumor recurrence after surgical resection or liver transplantation, suggesting that these tumors have aggressive characteristics. In this study, multivariate analysis showed that positive ezrin expression was independently associated with early recurrence after curative surgical resection in patients with hepatocellular carcinoma, as were multiple tumors. Ezrin 
is highly expressed in several types of human cancers and correlations between its immunoreactivity and patient outcome have been shown. ${ }^{28}$ Several in vitro ${ }^{29,30}$ studies have demonstrated that ezrin is involved in cancer cell invasion, migration, adhesion and proliferation, which may contribute to aggressive tumor progression and early recurrence after surgery. In hepatocellular carcinoma, Zhang et $a l^{14}$ have reported that ezrin expression was obviously upregulated in several cell lines with high metastatic potential, including MHCC97-H, in which CK19 expression was also identified, ${ }^{31}$ and was associated with cell proliferation, migration, and invasiveness. Although hepatocellular carcinoma recurrence in the remaining liver after curative surgical resection can reflect intrahepatic metastases that occur at the time of resection or metachronous, multicentric heptocarcinogenesis, recurrence of hepatocellular carcinoma with ezrin expression may arise from intrahepatic metastases, as recurrence occurs as early as within 30 months after surgical resection.

In conclusion, we have shown that ezrin is expressed in ductular reactions and intermediate hepatobiliary cells in cases of chronic hepatitis, as well as in $36 \%$ of cases of hepatocellular carcinoma that may be at least partly derived from hepatic progenitor cells. As ezrin expression was significantly associated with early recurrence of hepatocellular carcinoma after curative surgical resection, measurement of ezrin expression might be useful in identifying patients with an increased risk of early recurrence. Although functional analysis of ezrin in hepatocellular carcinoma is still insufficient, downregulation of ezrin expression in tumor tissues may be a potential therapeutic strategy for this type of hepatocellular carcinoma, as indicated in in vitro studies. ${ }^{14}$

\section{Disclosure/conflict of interest}

The authors have no conflict of interest to disclose.

\section{References}

1 El-Serag HB, Mason AC. Rising incidence of hepatocellular carcinoma in the United States. N Engl J Med 1999;340:745-750.

2 Shah SA, Cleary SP, Wei AC, et al. Recurrence after liver resection for hepatocellular carcinoma: risk factors, treatment, and outcomes. Surgery 2007;141: 330-339.

3 Sasaki A, Iwashita Y, Shibata K, et al. Improved longterm survival after liver resection for hepatocellular carcinoma in the modern era: retrospective study from HCV-endemic areas. World J Surg 2006;30:1567-1578.

4 Sasaki Y, Yamada T, Tanaka H, et al. Risk of recurrence in a long-term follow-up after surgery in 417 patients with hepatitis B- or hepatitis C-related hepatocellular carcinoma. Ann Surg 2006;244:771-780.
5 Shimozawa N, Hanazaki K. Longterm prognosis after hepatic resection for small hepatocellular carcinoma. J Am Coll Surg 2004;198:356-365.

6 Pandey D, Lee KH, Wai CT, et al. Long term outcome and prognostic factors for large hepatocellular carcinoma $(10 \mathrm{~cm}$ or more) after surgical resection. Ann Surg Oncol 2007;14:2817-2823.

7 Lee JS, Heo J, Libbrecht L, et al. A novel prognostic subtype of human hepatocellular carcinoma derived from hepatic progenitor cells. Nat Med 2006;12: $410-416$

8 Aishima S, Nishihara Y, Kuroda Y, et al. Histologic characteristics and prognostic significance in small hepatocellular carcinoma with biliary differentiation: subdivision and comparison with ordinary hepatocellular carcinoma. Am J Surg Pathol 2007;31:783-791.

9 Uenishi T, kubo S, Tamamoto T, et al. Cytokeratin 19 expression in hepatocellular carcinoma predicts early postoperative recurrence. Cancer Sci 2003;94:851-857.

10 Durnez A, Verslype C, Nevens F, et al. The clinicopathological and prognostic relevance of cytokeratin 7 and 19 expression in hepatocellular carcinoma. A possible progenitor cell origin. Histopathology 2006; 49:138-151.

$11 \mathrm{Wu}$ PC, Fang JW, Lau VK, et al. Classification of hepatocellular carcinoma according to hepatocellular and biliary differentiation markers. Clinical and biological implications. Am J Pathol 1996;149: 1167-1175.

12 Bonilha VL. Focus on molecules: ezrin. Exp Eye Res 2007;84:613-614.

13 Hunter KW. Ezrin, a key component in tumor metastasis. Trends Mol Med 2004;10:201-204.

14 Zhang Y, Hu MY, Wu WZ, et al. The membranecytoskeleton organizer ezrin is necessary for hepatocellular carcinoma cell growth and invasiveness. J Cancer Res Clin Oncol 2006;132:685-697.

15 Hirohashi S, Blum HE, Ishak KG, et al. Hepatocellular carcinoma. In: Hamilton SR, Aaltonen LA (eds). Tumour of the Digestive System. World Health Organization Classification of Tumours: Lyon, France, 2000, pp 158-172.

16 Bal N, Yildirim S, Nursal TZ, et al. Association of ezrin expression in intestinal and diffuse gastric carcinoma with clinicopathological parameters and tumor type. World J Gastroenterol 2007;27:3726-3729.

17 Sobin LH, Wittekind $\mathrm{CH}$, eds International Union Against Cancer: TNM Classification of Malignant Tumors, 6th edn. Wiley-Liss: New York, 2002.

18 Libbrecht L, Desmet V, Van Damme B, et al. Deep intralobular extension of human hepatic 'progenitor cells' correlates with parenchymal inflammation in chronic viral hepatitis: can 'progenitor cells' migrate? J Pathol 2000;192:373-378.

19 Falkowski O, An HJ, Ianus IA, et al. Regeneration of hepatocyte 'buds' in cirrhosis from intrabiliary stem cells. J Hepatol 2003;39:357-364.

20 Theise ND, Saxena R, Portmann BC, et al. The canals of Hering and hepatic stem cells in humans. Hepatology 1999;30:1425-1433.

21 Roskams TA, Theise ND, Balabaud C, et al. Nomenclature of the finer branches of the biliary tree: canals, ductules, and ductular reactions in human livers. Hepatology 2004;39:1739-1745.

22 Nagy P, Bisgaard HC, Santoni-Rugiu E, et al. In vivo infusion of growth factors enhances the mitogenic response of rat hepatic ductal (oval) cells after 
administration of 2-acetylaminofluorene. Hepatology 1996;23:71-79.

23 Okano J, Shiota G, Matsumoto K, et al. Hepatocyte growth factor exerts a proliferative effect on oval cells through the PI3K/AKT signaling pathway. Biochem Biophys Res Commun 2003;309:298-304.

24 Roskams T. Liver stem cells and their implication in hepatocellular and cholangiocarcinoma. Oncogene 2006;25:3818-3822.

25 Hsia CC, Evarts RP, Nakatsukasa H, et al. Occurrence of oval-type cells in hepatitis B virus-associated human hepatocarcinogenesis. Hepatology 1992;16:1327-1333.

26 Van Eyken P, Sciot R, Paterson A, et al. Cytokeratin expression in hepatocellular carcinoma: an immunohistochemical study. Hum Pathol 1988;19:562-568.

27 Yabushita K, Yamamoto K, Ibuki N, et al. Aberrant expression of cytokeratin 7 as a histological marker of progression in primary biliary cirrhosis. Liver 2001; 21:50-55.

28 Bruce B, Khanna G, Ren L, et al. Expression of the cytoskeleton linker protein ezrin in human cancers. Clin Exp Metastasis 2007;24:69-78.

29 Chuan YC, Pang ST, Cedazo-Minguez A, et al. Androgen induction of prostate cancer cell invasion is mediated by ezrin. J Biol Chem 2006;281: 29938-29948.

30 Martin M, Simon-Assmann P, Kedinger M, et al. DCC regulates celladhesion in human colon cancer derived HT-29 cells and associated with ezrin. Eur J Cell Biol 2006;85:769-783.

31 Ding SJ, Li Y, Tan YX, et al. From proteomic analysis to cilinical significance: overexpression of cytokeratin 19 correlates with hepatocellular carcinoma metastasis. Mol Cell Proteomics 2004;3:73-81. 